\title{
Climate change: Impact of increased ultraviolet radiation and water changes on eye health
}

\author{
Jyoti Jaggernath $^{1^{*}}$, Dominic Haslam ${ }^{2}$, Kovin S. Naidoo ${ }^{1,3}$ \\ ${ }^{1}$ African Vision Research Institute, Durban, South Africa; *Corresponding Author: j.jaggernath@brienholdenvision.org.za \\ ${ }^{2}$ Sightsavers, London, UK \\ ${ }^{3}$ Brien Holden Vision Institute, Durban, South Africa
}

Received 6 March 2013; revised 15 April 2013; accepted 10 May 2013

Copyright (c) 2013 Jyoti Jaggernath et al. This is an open access article distributed under the Creative Commons Attribution License, which permits unrestricted use, distribution, and reproduction in any medium, provided the original work is properly cited.

\begin{abstract}
Global climate change, a significant addition to the spectrum of environmental health threats, is projected to have widespread adverse effects on the earth over a multi-decadal time period. Consequently the planet's geological, biological and ecological systems, including human biology and health are expected to be altered. These effects are set to include an increase in adverse climate and weather events. The developing world carries a disproportionate burden of health implications that result from extreme climate and weather events, largely because they have limited capacity to respond to the cumulative impacts resulting from climate change. The developed world, however, is not immune to the impacts of climate change despite being highly industrialised and well serviced. In addition, there are a range of documented health impacts associated with climatic factors and a growing number of papers theorising how long-term climate change could impact on health. This article examines literature on the impact of climate change, specifically ultraviolet and water changes on eye health. Geographic and environmental factors that influence eye health, such as location and the spread of blindness causing diseases such as trachoma (bacterial infection of the eye) and onchocerciasis (parasitic disease in the eye) are also examined. The article aims to provide valuable information on the impacts of ultraviolet and water changes that are related to climate change and to propose recommendations that contribute to public health.
\end{abstract}

Keywords: Climate Change; Environment; Eye Diseases; Ultraviolet Radiation; Water Diseases;

\section{Human Exposure}

\section{INTRODUCTION}

Global climate change, a significant addition to the spectrum of environmental health threats [1] is projected to have widespread adverse effects on the earth over a multi-decadal time period [2]. Consequently the planet's geological, biological and ecological systems [3], including human biology and health are expected to be altered. As a result of the earth's changing climate, adverse weather and climate events are anticipated to occur more frequently. Extreme climate changes include events such as an increase in temperature and rainfall, extreme weather changes and a rise in sea level [4]. Meehl et al. (2009) states that all weather events today are influenced by climate change since weather now develops in a different environment than in the past. Natural variability continues to influence extreme weather; however, climate change has altered the natural limits, thus causing certain extreme weather events such as warming to occur more frequently and more intensely [5]. Cumulative impacts of climate change will be exerted significantly in the developing world, in terms of national capacity to respond to the disastrous nature of the health implications and diseases that occur as a result of extreme climate events [3]. Hales et al. (2003) assert that the developed world, however, is not immune to the impacts of climate change despite being highly industrialised and well serviced.

The health impacts resulting from climate change on human populations have over the years emerged as an important concern in recognition of the current climate extremes and the projected implications that may continue to escalate as a result of rapid changes in climate [6]. Climate change may affect health directly from exposure to an increased frequency of heat waves or indirectly from flooding or water shortages that facilitate the 
transmission of infectious diseases and favour the development of disease vectors [6]. McKenzie et al. (2003) points out that the potential health impacts of increased exposure to ultraviolet radiation (UVR) as a result of ozone depletion and water-related diseases are of growing concern in relation to climate change. Strong interactions exist between stratospheric ozone depletion and changes in climate-induced by increasing greenhouse gases (GHGs) [7]. Stratospheric ozone depletion impacts on climate and climate change impacts on the ozone. McKenzie et al. (2011) further point out that these changes are likely to decrease total stratospheric ozone in the tropics and increase total ozone at mid and high latitudes. Patterns of surface wind and rainfall may also be affected by changes in circulation that are induced by changes in stratospheric ozone. The prospective changes in stratospheric ozone and clouds may in the long-term result in large decreases in ultraviolet (UV) at high latitudes, where UV is already low; and to small increases at low latitudes, where it is already high [7]. This indicates a possible interaction between climate change and UVR. Exposure to UVR is increasing as stratospheric ozone depletion and global climate changes influence surface radiation levels [8-10]. Human health is affected directly from UVR exposure in the form of skin cancer and sunburns, immune system suppression, and eye damage, such as cataracts and photokeratitis [11].

The potential for vector-borne diseases are promoted by warming and environmental conditions which can also extend its geographic coverage [4]. Climate variability and change potentially stimulates the development of various vector borne diseases, such as onchocerciasis (parasitic disease that can result in blindness) [2].

In view of the potential effects from global climate change, this paper outlines the association between those effects, with specific emphasis being placed on eye diseases and increased UVR and changes in water quality, quantity and availability.

\section{INCREASES IN UVR AND OCULAR EFFECTS}

As stratospheric ozone depletion and global climate change influence surface radiation levels, human populations are increasingly being exposed to solar radiation. The primary source of radiation that reaches the eye is from sunlight [12]. The spectrum for solar radiation ranges from short-wavelength (100 nm) UVR to long wavelength $(1 \mathrm{~mm}$ or $100,000 \mathrm{~nm})$ far-infrared radiation. The physical spectrum of UVR ranges from 100 to 400 $\mathrm{nm}$. Ultraviolet radiation (UVR) carries the most potential for human harm despite it comprising of only $5 \%$ of the sun's energy, while solar UVR that reaches the Earth's surface comprises approximately 95\% UVA and
5\% UV-B [12]. Ultraviolet radiation (UVR) from sunlight is divided into three bands: UVA (315 to 400 nanometers), which causes tanning, aging of the skin and skin cancer; UV-B (280 to 315 nanometres) that can cause sunburn and skin cancer and UVC (280 - $100 \mathrm{~nm})$ which is almost completely absorbed by the atmospheric ozone and has minimal effects on health [13]. A high level of UVA that passes through the atmosphere remains unfiltered [6].

The World Health Organization (WHO) suggests that high levels of UVR are influenced by several geographical and environmental factors which include the high position of the sun, close proximity to the equator, increased altitude (increase by 5\% with every 1000 meters altitude), depletion of the ozone layer, and by surfaces that reflect the sun's rays, such as water bodies, sea foam and snow [14]. Lucas et al. (2006) indicate that UVR is responsible for an estimated $1 \%$ of the global burden of diseases (skin cancers, cataracts, other eye diseases, viral infections) that can result in death and disability. Broadband UVR can be detrimental to the eye and vision and cause damage to various ocular tissues [15]. The effects to the eye may be acute following long-term exposure or chronic due to long periods of exposure or repeated exposure to high levels of UVR [16]. Solar UVR usually affects the anterior structures of the eye and those areas adjacent to the eye. The anterior structures of the eye (cornea and lens) absorb more than $99 \%$ of UV-B radiation, which has high energy, and can therefore damage the anterior structure easily [16]. Oliva and Taylor (2005) state that while the retina is protected to some extent by the cornea and lens, it can also be damaged if exposed to UV-B. UVA is lower in energy but may cause damage to the eyes since it is absorbed much deeper into the tissues of the eye [13]. Ocular damages resulting from broadband UVR are discussed below.

\subsection{Cataracts}

Cataracts (clouding of the crystalline lens of the eye), is the sunlight-related eye disease (ophthalmoheliosis) with the most serious public health implications [16] and is the leading cause of avoidable blindness worldwide [17]. Quantifying the diverse range of health implications and risks associated with high levels of UV-B radiation are difficult as they are likely to be influenced by other human behavioural, ethic and geographical risk factors [16]. Epidemiological studies [18-20] however, have verified that certain types of cataract result from exposure to UVR. There are three primary types of age-related cataracts: nuclear sclerosis, cortical, and posterior sub capsular. As a person ages, any one type or a combination of the three types are likely to de- 
velop.

Ultraviolet radiation (UVR) and increased exposure to sunlight has been shown in many studies to be one of the major risk factors for cortical cataract [21,22]. In 2001 a study conducted on 1045 people who were older than 50 years in Iceland showed that there is a significant increase in the risks for two different grades of cortical opacification (the process of becoming cloudy or opaque) in people who spend more than 4 hours per day in the sun on weekdays [18]. The Chesapeake Bay Waterworm Study showed a positive relationship between UV-B exposure and cortical cataract [20]. UVR may have been a causative factor as watermen in the highest quartile had a three-fold increased risk for cortical cataract [21]. Prior to the Chesapeake Bay Waterworm Study, research conducted in Maryland re-affirmed the relationship between cortical cataract and sun exposure indicating a more modest $10 \%$ risk [19], since it was assumed that the population was representative of the United States (US). Based on this data, West and her colleagues developed risk estimates for the entire US population under conditions of ozone depletion [22]. Risk estimates were calculated for fixed levels of ozone depletion that ranged between $5 \%$ and $20 \%$ [19]. This indicated that the number of cortical cataract cases would increase between $1.3 \%$ and $6.9 \%$ by the year 2050. Additional reported risks from sun UV exposure in populations living at latitudes with differences in ambient UV exposure can be found in an Australian study where good correlations have been established between cataracts and ambient UV exposure in populations in Australia $[19,20]$. The study also showed that cortical cataract is relatively more prevalent than other types of cataract in populations living in temperate climates and the incidence increases toward lower latitudes.

\subsection{Refractive Error}

Over the last two decades, several studies have concluded that sunlight may be a risk factor for nuclear cataract [23-26]. Nuclear cataracts result from excessive nuclear sclerosis: a hardening and discoloration of the eye [27]. Nuclear cataracts, caused from nuclear sclerosis, have been found to cause myopic shifts (increased short sightedness) and significantly affect colour vision due to short wavelength light absorption [28]. Additionally, increased exposure to UVR from the sun may cause premature aging of the crystalline lens that could result in the increased prevalence of nuclear sclerosis and consequently myopia, a refractive condition (blurred vision), whereby the eye cannot clearly focus on images [29]. Based on this theory, the authors are of the opinion that increased exposure to UVR from the sun will result in a much earlier onset of this phe- nomenon, which will impact on more frequent spectacle prescription changes. Changes in spectacle prescriptions could have severe cost implications for health systems and may affect the poorest patients and in particular, the elderly.

\subsection{Presbyopia}

In addition to the range of ocular effects that are associated with climate change, research $[30,31]$ has shown that the anterior lens capsule and the refractive condition, presbyopia, are possibly related to increased exposure to sunlight and UV-B. Presbyopia is a condition in which the natural lens of the eye loses its ability to accommodate changes in focal length and focusing on close objects becomes difficult [32]. The condition results from the aging of the crystalline lens, and is generally prevalent in people who are over 40 years old. A study conducted in Somalia found a strong association between deformations of the anterior lens capsule and the central pupillary area (blind spot in the eye where the visual nerve leaves the retina), climatic droplet keratopathy (corneal degeneration due to prolonged climatic exposures) and reflected UV-B (a shortwavelength ultraviolet light) [31]. The risk of presbyopia may also be increased with greater exposure to UVR and higher climate temperatures [32]. Populations that live in close proximity to the equator, in areas that experience hot climate conditions and are exposed to high levels of sun are at a greater risk of developing presbyopia in their earlier years $[30,33]$. This is referred to as early onset presbyopia. In addition, presbyopia has been noted to increase 5 years earlier in the tropics than in the northern climates as a result of increased solar radiation [34].

\subsection{Eyelid Lesions}

Acute and chronic exposure of the eyelid to UVA and UV-B solar radiation causes UVR related damage to the skin of the eyelids as the skin becomes more susceptible to changes in melanin pigmentation, erythema (redness of the skin), and histopathological (dead tissue) production [12]. Neff et al. (1999) state that approximately $5 \%$ to $10 \%$ of all skin cancers occur on the eyelid and the area around the eyes which include the lid margins, canthi, eyebrows or adjacent area of the face. These areas may become susceptible to benign malignant lesions or tumours as a result of increased exposure to solar UVR. The most common types of skin lesions around the eyelids that frequently result from UVR exposure, according to [35] are basal cell carcinoma, squamous cell carcinoma, sebaceous cell carcinoma, and malignant melanoma. Basal cell carcinoma refers to a malignant lesion that is usually found on the lower 
eyelid or the inner canthus (nasal part) of the eye [35]. The incidence of basal cell carcinoma is highest in countries with intense sunlight exposure, such as Australia $(823$ per 100,000$)[36,37]$. Solar UVR exposure is known to be an important etiologic factor in the development of basal cell carcinoma [37], particularly in fair skinned individuals of middle age [38]. Squamous cell carcinoma of the eyelid is the second most common, invasive epithelial malignancy that occurs on the squamous layer of the epidermis (outermost layer of cells that make up the skin), and accounts for $5 \%-10 \%$ of periocular malignancies [38]. Ultraviolet radiation (UVR) damage and exposure to arsenic, hydrocarbons, radiation, or immunosuppressive drugs are risk factors for squamous cell carcinoma [39]. Newsome et al. (2004) point out that sebaceous carcinoma is a highly malignant tumour primarily found in the area of the upper eyelid. The tumour has a high recurrence rate with mortality being second only to malignant melanoma $(30 \%)[38,40]$. Laquis $(2010)$ affirms that the tumour has a high metastatic potential (spread of cancer) and accounts for less than $1 \%$ of all skin cancers around the eye. A major risk factor for developing malignant melanoma is a history of sunburns on the skin of the eyelid. An occurrence may increase with a greater UV exposure.

\subsection{Conjunctiva and Corneal Lesions}

UVB that reaches the eye is primarily absorbed by the epithelium (layer of cells) and Bowman layer (smooth layer of tissue) of the cornea (transparent, dome-shaped window covering the front of the eye) [41] however, acute and chronic exposure to UVR can cause acute and chronic pain and inflammatory changes in the exposed cornea or conjunctiva (thin membrane covering the inner surface of the eyelid and the white part of the eyeball) [12].

Chronic exposure to solar UVR is associated with other eye diseases including dry eyes, pterygium and squamous metaplasia (non-cancerous changes in the epithelial linings) or carcinoma (cancer emanating from an epithelial cell) [42]. The ocular equivalent of acute sunburn is photokeratitis and photoconjunctivitis [12]. These are discussed below:

- Pterygium: a wing-shaped, inflammatory and invasive growth that commonly occurs on the conjunctiva and cornea of the human eye is most commonly found in populations that are exposed to high levels of UV-B, UVR and particulate matter [12]. The condition is most prevalent and progresses more rapidly in populations situated near to the equator or at high altitudes. A number of environmental factors have been suggested to be associated with the development of pterygium including UVR, heat, cold, and wind. A study conducted in Australia reported a strong correlation between pterygia and environmental hazards [41]; while a significant relationship was found between the cumulative dose of solar UVA and UVB and the prevalence of pterygium in the more temperate climate of the northeastern US [25]. The higher prevalence of pterygium in rural areas, older populations and outdoor occupations has been attributed to the exposure of excessive amounts of sunlight $[43,44]$. Pterygium has also been found in studies to develop from dry eyes [45]. A dry eye condition can result from a dry climate, increased exposure to UVR, dust and increased winds [46]. Changes in tear function and a positive association between dry eye and pterygium have been published in several reports [46-48].

- Photokeratitis: a painful sunburn and inflammation of the cornea of the eye which results from excessive exposure of the eye to UV-B [33]. Moore et al. (2010) suggest that exposure of the eye to the sun on highly reflective snow fields at high elevations, which is known as snow blindness may cause direct injury to the corneal epithelium (outer layer). The corneal epithelium is affected by ultra violet radiation which results in the division of cells, fragmentation of cellular nuclear material, and loosening of the epithelial layer. Subsequently edema and congestion of the conjunctiva and a stippling of the corneal epithelium occur, which is known as superficial punctate keratitis [49]. Photo-keratitis in relation to solar UVR is commonly prevalent in individuals who participate in outdoor activities in environments with high reflective surfaces (beach activities, snow skiing, water sports) [50].

- Climatic Droplet Keratopathy (CDK): referred to as Labrador keratopathy, chronic actinic keratopathy, proteinaceous degeneration, and keratinoid degeneration is an acute syndrome that occurs after the eyes have been repeatedly exposed to ultraviolet irradiation [12]. The condition is generally confined to geographical areas with high levels of UV exposure and is a major cause of blindness in populations of arctic regions and tropical islands (places where reflections from snow, sand and water intensify the sunlight). Thus far, no direct link has been found between chronic UVA and UV-B exposure with climatic droplet keratopathy. However, the distribution of climatic droplet retinopathy in the Labrador region highly correlates with estimates of cumulative UVR exposure reflected by ice and snow [51]. The findings from the Chesapeake Bay Watermen study provide the supporting evidence for UV 
causation since the study showed that climatic droplet keratopathy was strongly associated with UV-B exposure.

\subsection{Retinal Lesions}

The relationship between an increased exposure to UVR and retinal damage is relatively less clear [52]. This is because the human retina (light-sensitive layer of tissue at the back of the inner eye), although well protected by UVR absorption of the cornea and lens (transparent structure that curves on both sides in the eye), is delicate and sensitive to light toxicity [12].

\subsection{Retinal Damage}

The retina can be damaged if exposed to UV-B [34]. There are three mechanisms of retinal damage that can occur following solar exposure: photochemical alteration, mechanical damage and thermal damage [53]. Limited research studies have been conducted on the impacts of increased UVR on the retina; thus chronic exposure to solar radiation and the effects on the retina need to be further explored. Most of the damage to the retina, resulting from UV rays, may be due to acute exposure from viewing the sun directly, however, limited knowledge exists regarding chronic exposure.

\subsection{Macular Degeneration}

Age-related macular degeneration (AMD) is an acquired retinal disorder which causes visual impairment, particularly in the Caucasian elderly and those with light irides (thin, circular structure in the eye which determines eye colour) [54]. The macula is the most sensitive region in the retina and is responsible for central detailed vision. Cumulative exposure to sunlight, especially to ultraviolet wavelengths may cause damage to the outer retina. However, research has shown that there is no clear association between UVR exposure and AMD [12]. This may be due to the ability of the lens to absorb almost all UV-B before it reaches the retina. The Chesapeake Bay watermen study [51] was unable to demonstrate a link between UVA and UV-B and AMD, however, the study showed a link between blue and high visible light exposure and AMD. The Beaver Dam Eye Study (BDES), on the other hand, suggested that a possible link between sunlight and AMD incidence and progression exists [55]. Despite these studies, not enough studies on the association between UVR exposure and AMD have been conducted and thus the association or the link needs to be further investigated.

\subsection{Uveal Melanoma}

The uvea is a pigmented, vascular structure consis- ting of the iris (thin, circular structure in the eye), ciliary body (structure in the eye that contributes to the eye's focussing ability and releases a transparent liquid aqueous humour), and choroid (layers of blood that lies between the retina and the white of the eye the sclera). Uveal melanoma, referred to as the most common primary intraocular malignancy of adults, is a neoplasm of the uveal tract that represents only $3 \%$ of all melanoma [56,57]. The risks of uveal melanoma are greater in European populations and occur less frequently in people of African origin [57]. There is limited and in general, vague supporting evidence [58-61] that shows a direct link between ocular (uveal) melanoma and UVR exposure. An increased risk of uveal melanoma from the effects of UVR exposure (severe eye burn) was found in a study of uveal melanoma in relation to ultraviolet light exposure and host factors [62]. A population-based study in Australia found a higher incidence of ocular melanoma from 1990 to 1998 in older men and in residents of rural areas [63], which may have been related to their exposure to high levels of UVR. However, the authors also mention that there were no findings from the study that supported strong latitude gradient in incidence. Despite the findings from the Australian study, there are other research studies that have shown that ocular melanomas have occurred in locations/regions that receive the highest exposure to solar radiation [12]. This suggests that UVR may actually play an indistinct but supporting role in the etiology of ocular melanoma in regions of high solar radiation exposure.

\section{IMPACT OF CLIMATE CHANGE ON WATER}

Climate change, particularly increasing temperature and changes in rainfall and the associated impacts on water resources and health have recently emerged as a matter of growing concern. Several studies have shown that increases in temperature have contributed significantly to warmer sea surface temperatures, higher precipitation levels, extensive periods of drought, and an accelerated melting effect on glaciers and ice cover [64]. As a result of extreme climate changes, the quality, quantity and availability of water supplies may be negatively impacted upon [65]. Increased temperature levels and decreased rainfall patterns are predicted to exacerbate existing shortfalls in water resources, particularly in the sub-tropics and mid-latitude, where most of the world's poor live [5], while an increase in rainfall is predicted to increase the frequency of floods and the replication and transmission of water-related vectors [66,67].

There are two categories of diseases that are related to water and which impacts on the eye: water-washed 
and water-related insect vectors [66,67]. Water-washed diseases such as trachoma (bacterial infection of the eyes that may result in blindness) occur when there is insufficient clean water for washing and for personal hygiene. Water-related insect vectors that transmit diseases such as onchocerciasis (parasitic disease that can result in blindness), are caused by contact with infectious pathogens and vectors that breed near contaminated water $[66,67]$. Increases in temperature can affect the distribution of the vector and the effectiveness of pathogen transmission through the vector [68], while increases in rainfall will increase surface water and the geographic coverage and spread of vectors [69]. This situation may create new breeding sites for some vectors and therefore an increase in some vector populations and in the transmission of infectious pathogens to human populations [69]. The literature above has shown that climate variability and change is likely to have substantial human health implications, which may even result in mortality in some extreme cases. However, the following sections places particular focus on the potential impacts of climate change on water in relation to eye diseases.

\subsection{Trachoma}

Trachoma is a neglected tropical disease which is the second leading cause of blindness (after cataracts) and the first leading cause of preventable infectious blindness in the world [70,71]. Trachoma is a chronic conjunctivitis with different manifestations that continues to plague many of the remote and poor areas of Africa, Asia, Australia, Latin America and the Middle East [19,72]. The disease is the leading cause of blindness in over 6 million people worldwide and is active in more than 84 million people in 55 countries [73]. Trachoma is particularly prevalent in countries that are hot and dry and where access to clean water, proper sanitation and health care is limited [73]. Active trachoma refers to an inflammatory early stage of the disease that is caused by recent infection with Chlamydia trachomatis [74], an ocular bacteria that is commonly more prevalent in pre-school children [75]. WHO (2006) states that frequent exposure to trachoma infection creates scarring of the eyelid which leads to entropion, subsequently causing the eyelids to turn inwards and the eyelashes to scratch the cornea (trichiasis). This eventually leads to conjunctivitis, corneal scarring, complete corneal opacity and blindness. The disease has been targeted for global elimination by the year 2020 in a resolution adopted by WHO [76,77].

The prevalence of trachoma is associated with climatic and environmental factors such as humidity, evaporation, increased sun reflections, latitude, UVR and rainfall [78]. Individual and environmental risk factors, including climatic variations may be important determinants that are associated with trachoma; however, transmission of the disease can also occur mechanically through flies [79]. Moreover, conjunctivitis and trachoma spread more easily if the quantity of water available for personal hygiene and sanitation is limited. Climate change, particularly increasing temperatures and changing rainfall patterns will eventually affect water supplies. Leder et al. (2002) asserts that long periods of drought will lead to water shortages, thereby leading to further decrease in access to clean water in underserved communities. In times of shortage, water is used for cooking rather than personal hygiene and sanitation [80]. This will increase the risk of trachoma occurring.

\subsection{Onchocerciasis}

Onchocerciasis, more commonly referred to as river blindness, is an eye infection that is caused by the bite of a parasitic worm Onchocerca Volvulus [81]. The disease is called river blindness because the blackfly that causes infection breeds in fast-flowing rivers and blindness may be caused as a result of being infected [69]. Blindness results from the invasion of microfilaria that is produced by the worm, which can damage the structure of the eye [69]. Onchocerciasis is prevalent in 27 sub-Saharan African countries and 6 Latin American countries, including inter-tropical areas where there are rivers. The disease affects an estimated 42 million people worldwide, of which 99 percent can be found in sub-Saharan Africa [4]. In Africa, 90 million people are at risk of contacting the infectious disease [82], particularly in Central and West Africa. Thus, onchocerciasis is regarded as one of the central causes of blindness in Africa. The disease has also been noted to impact in economic losses in the infected regions (annual loss of over 1 million disability-adjusted life years) [83], due to both increased direct morbidity to those affected, and increased burden of care on their families.

Climate change, more specifically an increase in rainfall patterns, is projected to spread vector-borne diseases such as onchocerciasis and place additional stresses on ecosystems, the rural poor, marginalised and vulnerable people, particularly children and the elderly [4]. This situation can be attributed to the assertion that the onchocerciasis vector requires fast-flowing water for successful reproduction [84], whilst the adult vector can also be spread by intense winds. Vectors travel hundreds of kilometres on wind currents and this could eventually lead to the colonisation of blackflies in new habitats, thereby introducing and facilitating the spread of onchocerciasis [6]. High rainfall intensity is projected to facilitate the transport of vector-borne diseases 
and parasites from one locality to another, as rivers overflow and river velocity increases [84]. In addition, excessive wastewater from sewer treatment systems may be discharged directly into surface water bodies during seasons of heavy rainfall favouring the development of larva and adult vectors [85].

\section{CONCLUSIONS}

There is an overall lack of evidence directly linking predictions of climate change with eye health. However, available literature reviewed in this article on the links between eye health and climatic factors suggest that long-term climate changes could have adverse effects on eye health and visual impairment-related morbidity.

Health promotion/ prevention strategies are critically needed to create awareness on human eye health and climate related impacts. In addition to health promotion/ prevention strategies, the eye health community should adopt an approach to ocular morbidity which necessitates active campaigning for the protection of the environment and for stringent prevention and mitigation strategies. With this in mind, further research into and investigation of preventive measures and programmatic responses should be undertaken. These could include UVR protection elements to refractive error correction and spectacle manufacture and distribution programmes; increased emphasis on the elimination of trachoma and onchocerciasis in advance of climatic changes potentially increasing the factors favourable to the transmission of these diseases, and further research and guidance on the likely impacts of climatic changes such as an increase or decrease in temperature on eye health conditions.

\section{ACKNOWLEDGEMENTS}

The authors would like to thank Sightsavers for financially supporting the publication of this article. Additional acknowledgment is extended to Dr. Tom Were Okello for reviewing the article.

\section{REFERENCES}

[1] McMichael, A.J., Campbell-Lendrum, D., Ebi, K., Githeko, A., Scheraga, J. and Woodward, A. (2003) Climate change and human health: Risks and responses. World Health Organization, Geneva.

[2] Samet, J. (2010) Public health: Adapting to climate change. Resources for the Future. www.rff.org/rff/documents/RFF-IB-10-06.pdf

[3] Hales, S., Edwards, S.J. and Kovats, R.S. (2003) Impacts on health of climate extremes. In: McMichael, A.J., et al., Eds., Climate Change and Human Health: Risks and Responses, World Health Organization, Geneva, 79-102.

[4] Davies-Cole, J.O. (2010) Climate change and the spread of vector-borne diseases. 20. http://globalnetwork.org/

[5] Meehl, G.A., Tebaldi, C., Walton, G., Easterling, D. and
McDaniel, L. (2009) Relative increase of record high maximum temperatures compared to record low minimum temperatures in the US Geophysics. Geophysical Research Letters, 36, Article ID: L23701. doi:10.1029/2009GL040736

[6] McMichael, A.J., Campbell-Lendrum, D., Kovats, S. and Edwards, S. (2004) Global climate change. In: Ezzati, M., Lopez, A., Roders, A., et al., Eds., Comparative Quantification of Health Risks, Global and Regional Burden of Disease Attributable to Selected Major Risk Factors, World Health Organization, Geneva, 1543-1650.

http://www.who.int/publications/cra/chapters/volume2/15 43-1650.pdf

[7] McKenzie, R.L., Aucamp, P.J., Bais, A.F., Björn, L.O., Ilyas, M. and Madronich, S. (2011) Ozone depletion and climate change: Impacts on UV radiation. Photochemical \& Photobiological Sciences, 10, 182-198. doi:10.1039/c0pp90034f

[8] World Health Organization (2003) Artificial tanning sunbeds risks and guidance. WHO, Geneva. http:// www.who.int/ uv/publications/en/sunbeds.pdf

[9] Zepp, R.G., Erickson III, D.J., Paul, N.D. and Sulzberger, B. (2007) Interactive effects of solar UV radiation and climate change on biogeochemical cycling. Photochemical \& Photobiological Sciences, 6, 286-300. doi:10.1039/b700021a

[10] McKenzie, R.L., Bjorn, L. and Bais, A. (2003) Changes in biologically active ultraviolet radiation reaching the earth's surface. Photochemical \& Photobiology Sciences, 2, 5-15. doi:10.1039/b211155c

[11] De Fabo, E. and Bjorn, L.O. (2000) Ozone depletion and UV-B radiation. In: Nuttall, M. and Callaghan, T.V. Eds., The Arctic Environment, People, Policy. Harwood Academic Publishers, 555-573.

[12] Oliva, M.S. and Taylor, H. (2005) Ultraviolet radiation and the eye. International Ophthalmology Clinical, 45, $1-17$.

[13] Lucas, R., McMichael, T., Smith, W. and Armstrong, B. (2006) Solar ultraviolet radiation global burden of disease from solar ultraviolet radiation. Environmental Burden of Disease Series, No. 13, World Health Organization, Public Health and the Environment, Geneva.

[14] World Health Organisation (2009) Ultraviolet radiation and human health. Fact Sheet No. 305. www.who.int/globalchange/publicationsclimchange.pdf

[15] Oriowo, O.M., Cullen, A.P., Schirmer, K., Chou, B.R., Bols, N.C. and Sivak, J.G. (2002) Evaluation of porcine lens and a fluorescence assay approach for in vitro ocular toxicological investigations. Alternatives to Laboratory Animals (ATLA), 30, 505-513.

[16] De Gruijl, F.R., Longstreth, J., Norval, M., Cullen, A.P., Slaper, H., Kripke, M.L., Takizawa., Y. and van der Leun, J.C. (2003) Health effects from stratospheric ozone depletion and interactions with climate change. Photochemical Photobiology. Science, 2, 16-28. doi:10.1039/b211156j

[17] Lui, B., Xu, L., Wang, Y.X. and Jonas, J.B. (2009) Prevalence of cataract surgery and postoperative visual out- 
come in greater Beijing: The Beijing eye study. Ophthalmology, 16, 1322-1331.

[18] Katoh, N., Jonasson, F., Sasaki, H., Kojima, M., Ono, M., Takahashi, N. and Sasaki, K. (2001) Cortical lens opacification in Iceland. Risk factor analysis-Reykjavik Eye Study. Acta Ophthalmology Scand, 79, 154-159. doi:10.1034/j.1600-0420.2001.079002154.x

[19] West, S.K., Duncan, D.D., Munoz, B., Rubin, G.S., Fried L.P., Bandeen-Roche, K. and Schein, O.D. (1998) Sunlight exposure and risk of lens opacities in a populationbased study: The Salisbury eye evaluation project. JAMA, 280, 714-718. doi:10.1001/jama.280.8.714

[20] Schein, O.D., Steinberg, E.P. and Javitt, J.C. (1994) Variation in cataract surgery practice and clinical outcomes. Ophthalmology, 101, 1142-1152.

[21] Taylor, M.R., Rubin, E.S. and Hounshell, D.A. (2005) Control of $\mathrm{SO}_{2}$ emissions from power plants: A case of induced technological innovation in the US. Technological \& Social Change, 72, 697-718.

[22] West, S.K. and Valmadrid, C.T. (1995) Epidemiology of risk factors for age-related cataract. Survey of Ophthalmology, 39, 323-334. doi:10.1016/S0039-6257(05)80110-9

[23] Hollows, F. and Moran, D. (1981) Cataract the ultraviolet risk factor. Lancet, 2, 1249-1250. doi:10.1016/S0140-6736(81)91490-2

[24] Hiller, R., Sperduto, R.D. and Ederer, F. (1986) Epidemiologic associations with nuclear, cortical, and posterior subcapsular cataracts. American Journal of Epidemiology, 124, 916-925.

[25] Taylor, H.R., West, S.K. and Rosenthal, F.S. (1988) Effect of ultraviolet radiation on cataract formation. New England Journal of Medicine, 319, 1429-1433. doi:10.1056/NEJM198812013192201

[26] McCarty, C.A., Fu, C.L. and Taylor, H.R. (2000) Epidemiology of pterygium in Victoria, Australia. British Journal of Ophthalmology, 84, 289-292. doi:10.1136/bjo.84.3.289

[27] Richter, C.U. and Fine L.C. (2009) Management of cataracts. In: Allen, H., et al., Ed., 6th Edition, Primary Care Medicine: Office Evaluation and Management of the Adult Patient, Lippincott Williams \& Wilkins, Philadelphia, $1367-1370$

[28] Pesudovs, K. and Elliott, D. (2001) Cataract assessment. Part 2, Optician, 222. www.optometryonline.net

[29] Saito, Y., Lewis, J.M., Park, I., Ikuno, Y., Hayashi, A., Ohji, M. and Tano, Y. (1999) Nonvitrectomizing vitreous surgery. A strategy to prevent postoperative nuclear sclerosis. Ophthalmology, 106, 1541-1545. doi:10.1016/S0161-6420(99)90451-7

[30] Stevens, M.A. and Bergmanson, J.P. (1989) Does sunlight cause premature aging of the crystalline lens? Journal of the Optometric Association, 60, 660-663.

[31] Johnson, G., Minassian, D. and Franken, S. (1989) Alterations of the anterior lens capsule associated with climatic keratopathy. British Journal of Ophthalmology, 73, 229234. doi:10.1136/bjo.73.3.229

[32] VISION2020 Information Sheet (2007) Refractive error.
www.vision2020australia.org.au//Fact-Sheet-Refractive-E $\underline{\text { rror.rtf }}$

[33] Cavallerano, A. Cummings, J.P., Freeman, P.B., Jose, R.T., Shinseki, L.J. and Potter J.W. (1994) Optometric clinical practice guideline. Care of the patient with age-related macular degeneration. Reference Guide for Clinicians, American Optometric Association, Lindbergh Blvd. http://www.aoa.org/documents/CPG-6.pdf

[34] Miller, D. and Scott, C.A. (2010) Chapter 6-Light damage to the eye.

http://medtextfree.wordpress.com/2010/10/11/chapter-6-li ght-damage-to-the-eye/

[35] Laquis, S.J. (2010) Eyelid lesions. Benign and malignant. Health and Wellness. Collier Edition. www.laquis.net/download/132/HealthWellnessCollier18.p df

[36] Giles, G.G., Marks, R. and Foley, P. (1988) Incidence of non-melanocytic skin cancer treated in Australia. British Medical Journal, 296, 13-17. doi:10.1136/bmj.296.6614.13

[37] Marks, R. (1995) An overview of skin cancers. Cancer, 75, 607-612.

[38] Fong, K.C.S. and Malhotra, R. (2005) Common eyelid malignancies clinical features and management options. Clinical, 30-34.

http://www.optometry.co.uk/uploads/articles/aff9794de0a 3c3caead621804b5ff111Malhora181105.pdf

[39] Donaldson, G.C., Keatinge, W.R. and Nayha, S. (2003) Changes in summer temperature and heat-related mortality since 1971 in north Carolina, south Finland, and southeast England. Environmental Research, 91, 1-7. doi:10.1016/S0013-9351(02)00002-6

[40] Zürcher, M., Hintschich, C.R., Garner, A., Bunce, C. and Collin, J.R. (1998) Sebaceous carcinoma of the eyelid: A clinic pathological study. British Journal of Ophthalmology, 82, 1049-1055. doi:10.1136/bjo.82.9.1049

[41] Al Bdour, M. and Al Latayfeh, M.M. (2004) Risk factors for pterygium in an adult Jordanian population. Acta Ophthalmology Scandinavica, 82, 64-67.

[42] Kennedy, M., Kim, K.H., Harten, B., Brown, J., Planck, S., Meshul, C., Edelhauser, H., Rosenbaum, J.T., Armstrong, C.A. and Ansel, J.C. (1997) Ultraviolet irradiation induces the production of multiple cytokines by human corneal cells. Investigative Ophthalmology of Visual Science, 38, 2483-2491.

[43] McCarthy, F.D., Wolf, H. and Wu, Y. (2000) The growth costs of malaria. NBER Working Paper No. 7541, National Bureau of Economic Research, Cambridge. http://www.nber.org/papers/w7541.pdf? new_window =1

[44] Threlfall, T.J. and English, D.R. (1999) Sun exposure and pterygium of the eye: A dose-response curve. American Journal of Ophthalmology, 128, 280-287.

[45] Lu, J., Wang, Z., Lu, P., Chen, X., Zhang, W., Shi, K., Kang, Y., Ke, L. and Chen, R. (2009) Pterygium in an aged Mongolian population: A population-based study in China. Eye, 23, 421-427. doi:10.1038/sj.eye.6703005

[46] Saleem, A., Matthews, J.C., Ranson, M., Callies, S., André, V., Lahn, M., Dickinson, C., Prenant, C., et al. (2011) 
Molecular imaging and pharmacokinetic analysis of Carbon-11 labeled antisense oligonucleotide LY2181308 in cancer patients. Theranostics, 1, 290-301.

[47] Ishioka, R., Uemura, M., Matsumoto, K., et al. (2001) First detection of the growing humps at the rapidly rising stage of dwarf novae AL Com and WZ Sge. IAU Circular, Japan. http://arxiv.org /pdf/astro-ph /01 11432.pdf

[48] Ergin, A. and Bozdogan, E.O. (2001) Study on tear function abnormality in pterygium. Ophthalmologica, 215, 204-208. doi:10.1159/000050859

[49] Valdivia, C. and Puttatuci, A. (2011) Glaucoma and eye disease information. http://www.glaucoma-eye-info.com/

[50] Moore, L.A., Hussey, M., Ferreira, J.T. and Wu, B. (2010) Review of photokeratitis: Corneal response to ultraviolet radiation (UVR) exposure. South African Optometrist, 69, 123-131.

[51] Taylor, H.R., West, S.K., Rosenthal, F.S., Munoz, B., Newland, H.S. and Emmett, E.A. (1989) Corneal changes associated with chronic UV irradiation. Arch Ophthalmology, 107, 1481-1484.

[52] Lichtenstein, D.L., Toh, K., Doronin, K., Tollefson, A.E. and Wold, W.S. (2004) Functions and mechanisms of action of the adenovirus E3 proteins. International Reviews of Immunology, 23, 75-111.

[53] Turki, A., Al-Turki, M.D., Mohammad Al-Amry, M.D. (2007) Optical coherence tomography in acute solar maculopathy. Saudi Journal of Ophthalmology, 21, 38-40.

[54] Oduntan, O.A., Clarke-Farr, P., Hansraj, R. and Carlson, A. (2010) Awareness of the phototoxic effects of sunlight among South African university students. South African Optometrist, 69, 146-151.

[55] Tomany, S.C., Cruickshanks, K.J. and Klein, R. (2004) Sunlight and the 10-year incidence of age-related maculopathy: The beaver dam eye study. Formerly Archives of Ophthalmology, 122, 750-757. doi:10.1001/archopht.122.5.750

[56] Singh, A.D., Rennie, I.G., Seregard, S., Giblin, M. and McKenzie, J. (2004) Sunlight exposure and pathogenesis of uveal melanoma. Survey Ophthalmology, 49, 419-428.

[57] Kincaid, M.C. (1998) Uveal melanoma. Cancer Control, 5, 299-309.

[58] Seddon, J.M., Gragoudas, E.S., Glynn, R.J., Egan, K.M., Albert, D.M. and Blitzer, P.H. (1990) Host factors, UV radiation, and risk of uveal melanoma. A case-control study. Formerly Archives of Ophthalmology, 108, 12741280. doi:10.1001/archopht.1990.01070110090031

[59] Gallagher, R.P., Elwood, J.M. and Rootman, J. (1985) Risk factors for ocular melanoma: Western Canada melanoma study. Journal of national cancer institute, $\mathbf{7 4}$, 775-778.

[60] Holly, E.A., Aston, D.A. and Char, D.H. (1990) Uveal melanoma in relation to ultraviolet light exposure and host factors. Cancer Research, 50, 5773-5777.

[61] Tucker, M.A., Shields, J.A. and Hartge, P. (1985) Sunlight exposure as risk factor for intraocular malignant melanoma. The New England Journal of Medicine, 313, 789-792.

[62] Elizabeth, A.H., Diana, A.A. and Devron, H.C. (1990)
Uveal melanoma in relation to ultraviolet light exposure and host factors. Cancer Research, 50, 5773-5777.

[63] Vajdic, C.M., Kricker, A. and Giblin, M. (2003) Incidence of ocular melanoma in Australia from 1990 to 1998. International Journal of Cancer, 105, 117-122.

[64] Almendares, J. and Epstein P.R. (2011) Climate change and health vulnerabilities. State of the World. In: Starke, L., Ed., State of the World: Into a warming world, Norton \& Company Ltd., Castle House, London, 78-80. http://www.worldwatch.org/files/pdf/State\%20of\%20the \%20World\%202009.pdf

[65] Morrison, J., Morikawa, M., Murphy, M. and Schulte, P. (2009) Water scarcity \& climate change: Growing risks for businesses and investors-A Ceres report.

http://www.pacinst.org/reports/business_water_\%20clima te/\%20full report.pdf

[66] Gleick, P.H. (2002) Dirty water: Estimated deaths from water-related diseases 2000-2020. Pacific Institute Research Report. Pacific Institute for Studies in Development, Environment, and Security. www.pacinst.org

[67] Gubler, D.J., Reiter, P., Ebi, K.L., Yap, W., Nasci, R. and Patz, J.A. (2001) Climate variability and change in the United States: Potential impacts on vector- and rodentborne diseases. Environmental Health Perpectives, 109, 223-233.

[68] Epstein, P.R. (2001) Climate change and emerging infectious diseases. Microbes and Infection, 3, 747-754. doi:10.1016/S1286-4579(01)01429-0

[69] Thylefors, B. (1990) The World Health Organization's programme for the prevention of blindness. International Ophthalmology, 14, 211-219.

[70] Resnikoff, S., Pascolini, D., Etya'ale, D., Kocur, I. and Pararajasegaram, R. (2004) Global data on visual impairment in the year 2002. Bulletin of the World Health Organisation, 82, 844-851.

[71] World Health Organization (1998) Global elimination of blinding trachoma. Geneva World Health Assembly. http://www.who.int/pbd/publications/trachoma/en/get jan 1998.pdf

[72] Mariotti, S. (2004) New steps toward eliminating blinding trachoma. The New England Journal of Medicine, 351, 2004-2007.

[73] Baggaley, R.F., Solomon, A.W., Kuper, H., Polack, S., Massae, P.A., Kelly, J., Safari, S., Alexander, N.D., Courtright, P. and Foster, A. (2006) Distance to water source and altitude in relation to active trachoma in Rombo District, Tanzania. Tropical Medicine \& International Health, 11, 220-227. doi:10.1111/j.1365-3156.2005.01553.x

[74] Bailey. R., Duong, T., Carpenter, R., Whittle, H. and Mabey, D. (1999) The duration of human ocular Chlamydia trachomatis infection is age dependent. Epidemiology and Infection, 123, 479-486.

[75] World Health Organisation (2006) Trachoma: A guide for programme managers. International Trachoma Initiative, London School of Hygiene and Tropical Medicine, Geneva.

whqli-doc.who.int/publications/2006/9241546905_eng.pdf 
[76] Kuper, H., Solomon, A.W., Buchan, J., Zondervan, M., Foster, A. and Mabey, D. (2003) A critical review of the SAFE strategy for the prevention of blinding trachoma. The Lancet Infectious Diseases, 3, 372-381.

[77] Prost, A. and Negrel, A.D. (1989) Water, trachoma and conjunctivitis. Bulletin of the World Health Organization, 67, 9-18.

[78] Smith, J.L., Haddad, D., Polack, S., Harding-Esch, M., Hooper, P.J., Mabey, D.C., Solomon, A.W. and Brooker, S. (2011) Mapping the global distribution of trachoma: Why an updated atlas is needed. PLoS Neglected Tropical Diseases, 5, e973. www.plosntds.org

[79] Leder, K., Sinclair, M.I. and McNeil, J.J. (2002) Water and the environment: A natural resource or a limited luxury? The Medical Journal of Australia, 178, 142.

[80] Centers for Disease Control and Prevention (2010) Parasites-Onchocerciasis (also known as River Blindness). http://www.cdc.gov/parasites/onchocerciasis/

[81] Basanez, M.G., Pion, S.D.S., Churcher, T.S., Breitling,
L.P., Little, M.P. and Boussinesq, M. (2006) River blindness: A success story under threat? Plos Medicine, 3, 1454-1460. doi:10.1371/journal.pmed.0030371

[82] World Health Organisation (2010) Prevention of blindness and visual impairment: Onchocerciasis (River Blindness)-disease information.

http://www.who.int/blindness/partnerships/onchocercisis disease information/en/index html

[83] Patz, J.A., Graczyk, T.K., Gellera, N. and Vittor, A.Y. (2000) Effects of environmental change on emerging parasitic disease. International Journal for Parasitology, 30, $1-11$.

[84] Neff, A.G. and Carter, K.D. (1999) Benign eyelid lesions. In: Yanoff, M. and Duker, A.S., Eds., Ophthalmology, Mosby, London, 1422-1433.

[85] Newsome, P., Romeu, M.L., Seguiti, M., Stenson, S. and Yassein, W. (2004) The effects of ultraviolet and visible light on the eye. Transitions Optical, Inc., Canada. 